\title{
The Psychology Behind Helping and Prosocial Behaviors: An Examination from Intention to Action
}

Jennifer L. Silva

Louisiana State University at Baton Rouge

Loren D. Marks

Brigham Young University - Provo, loren_marks@byu.edu

Katie E. Cherry

Louisiana State University at Baton Rouge

Follow this and additional works at: https://scholarsarchive.byu.edu/facpub

Part of the Other Social and Behavioral Sciences Commons

\section{Original Publication Citation}

Silva, J., Marks, L. D., \& Cherry, K. (2009). The psychology behind helping and prosocial behaviors: An examination from intention to action in an adult population. In K. Cherry (ed.), Lifespan Perspectives on Natural Disasters: Coping with Katrina, Rita and other Storms (pp. 219-240). New York: Springer.

\section{BYU ScholarsArchive Citation}

Silva, Jennifer L.; Marks, Loren D.; and Cherry, Katie E., "The Psychology Behind Helping and Prosocial Behaviors: An Examination from Intention to Action" (2009). Faculty Publications. 4904.

https://scholarsarchive.byu.edu/facpub/4904

This Book Chapter is brought to you for free and open access by BYU ScholarsArchive. It has been accepted for inclusion in Faculty Publications by an authorized administrator of BYU ScholarsArchive. For more information, please contact ellen_amatangelo@byu.edu. 


\title{
Chapter 11 \\ The Psychology Behind Helping and Prosocial \\ Behaviors: An Examination from Intention \\ to Action
}

\author{
Jennifer L. Silva, Loren D. Marks, and Katie E. Cherry
}

\begin{abstract}
When disasters strike, many people rise to the challenge of providing immediate assistance to those whose lives are in peril. The spectrum of helping behaviors to counter the devastating effects of a natural disaster is vast and can be seen on many levels, from concerned individuals and community groups to volunteer organizations and larger civic entities. In this chapter, we examine the psychology of helping in relation to natural disasters. Definitions of helping behaviors, why we help, and risks of helping others are discussed first. Next, we discuss issues specific to natural disasters and life span considerations, noting the developmental progression of age-related, altruistic motivations. We present a qualitative analysis of helping behaviors based on interviews with participants in the Louisiana Healthy Aging Study (LHAS; see Cherry, Silva, \& Galea, Chapter 9). These data show that some people directly engaged in helping behaviors to further the relief effort after Hurricanes Katrina and Rita, while others spoke of helping indirectly through their associations with local churches and faith-based organizations that provided storm relief. Implications for helping behaviors and intentions to help in a post-disaster situation are considered.
\end{abstract}

\section{Introduction}

In the wake of one of the largest natural disasters in United States history, persons from across the globe opened their homes, hearts, and wallets to those affected by Hurricanes Katrina and Rita. In 2006 it was reported that citizens and humanitarian organizations had contributed a combined total of 3 billion dollars to relief efforts (Indiana University Center on Philanthropy, 2007). This same organization also reported that a majority of surveyed US households provided monetary donations for victims of the Gulf Coast storms. While financial assistance was a prominent form of aid, it was not the only manner of aid exhibited. There were

K.E. Cherry $(\bowtie)$

Department of Psychology, Louisiana State University, Baton Rouge, LA 70803-5501, USA

e-mail: pskatie@1su.edu 
many persons who traveled to the devastated regions of Louisiana and Mississippi to donate their time and services. Many worked tirelessly by handing out food and clothing, locating missing persons, rescuing those stranded in their houses, organizing relief efforts, and counseling persons who lost their homes and possessions (see Allen and Wayne, Chapter 8). In addition, those not able to travel to disaster areas may have held community bake sales or collected canned goods in order to make their own donation to the Gulf Coast recovery. All of these described actions can be defined as prosocial behaviors, which are those actions that help or benefit another individual or group (Eisenberg \& Fabes, 1998). Furthermore, these behaviors may result from some level of concern or empathy on the part of the helper and provide a benefit to the recipient (Dovidio, Palivan, Schroeder, \& Penner, 2006; Eisenberg \& Fabes, 1998).

In recent years, the demonstration of prosocial behaviors has increased and was especially evident after the attacks of 9/11 (Pyszczynski, Solomon, \& Greenburg, 2003). People from across the country flocked to blood centers to give blood to the survivors. Some established trust funds for the children of those who perished in the twin towers. Millions in donations poured into the various humanitarian organizations across the nation. In the days and weeks following the attacks of 9/11, the United States of America became the face of humanity, compassion, and camaraderie.

The outpouring of these helping behaviors prompted psychologists to investigate those factors that motivate individuals to help one another during or following a catastrophic event. The origins of these behaviors have sparked scientific interest for decades and have led to a variety of hypotheses that are discussed in this chapter (see also Dovidio et al., 2006). We adopt a life span perspective by examining how an individual's age can influence the manner in which he/she can make unique contributions to their local community. In particular, we present data from the Louisiana Healthy Aging Study (LHAS), which has examined the impact of Hurricanes Katrina and Rita on its participants (see Cherry et al., Chapter 9). During interviews with a sample of LHAS participants, it became clear that many had either directly or indirectly helped those affected by Hurricanes Katrina and Rita, and others had received storm-related assistance. While investigating the presence/impact of helping behaviors was not an initial target of the LHAS investigation, participant reports provided a clear rationale for further investigation.

\section{Why Do We Help?}

The reason behind why individuals help one another is not as straightforward as some might predict. Many factors have been identified that may influence prosocial behaviors. For instance, biological theories of helping behavior consider the role of genetics, evolution, and survival of the fittest. Internal factors like empathetic responses, a negative personal state, and other personal motivations may also be involved. Individual differences in personality, current mood, and results from an 
internal cost-benefit analysis may impact ones' decision to help (for a review, see Dovidio et al., 2006). These different views are discussed next to offer insight into the fundamentals of prosocial behaviors and provide a context for understanding the psychology of helping as it applies to post-disaster reactions.

\section{Kin Selection View of Prosocial Behavior}

One of the more naturalistic explanations for prosocial behavior branches from evolutionary psychology and early experiments examining genetics and species survival (Hamilton, 1963, 1964). Early research documented basic helping behaviors in nonhuman species, which many assume to have a limited (or non-existent) emotional relationship with other members of their species. From these observations, Hamilton was the first to theorize that prosocial behavior could possess some genetic origin. This rationale stemmed from the idea that prosocial behaviors could lead to species fitness. Hamilton hypothesized that without help between cohort members, species survival would be in jeopardy and extinction would become eminent. Consequently those members who actively engage in and receive prosocial behaviors are those most likely to survive, pass on their genes to future generations, and ultimately contribute to species development.

Using Hamilton's rationale, helping is thought to be a genetically programmed, innate behavior. For instance, visualize a young mother and her newly born child. Across many species, the mother commonly reduces the level of attention and help devoted to older offspring, in order to attend to younger and less self-sufficient ones. Hamilton $(1963,1964)$ assumes this is done because older offspring are more capable, due to their acquisition of survival skills. The mother chooses the younger offspring to ensure their survival. They not only receive more attention and care from their mother, but a mother may forgo her own physiological and safety needs to provide for her young. In contrast, mothers who fail to care for their young are those least likely to pass their genetic code and ensure species survival. Thus, the kin selection theory (Hamilton, 1963, 1964) assumes that members of the species who possess a genetic code for prosocial behavior will be the most likely to reproduce.

The kin selection theory branch of evolutionary theories relates to John Bowlby's attachment theory (Bowlby, 1969, 1988). Attachment theory offers psychological and evolutionary explanations for human relationships. Bowlby's early work centered on the strong, stable, and secure bond between an infant and a caregiver, but his conclusions were eventually applied to adult relationships. According to attachment theory, infants are thought to be dependent for the sole purpose of survival, and thus need a safe and strong relationship with their caregiver (usually their mother). Infants will eventually use their caregiver as a secure base from which they explore the world. Some researchers have argued that Hamilton's kin selection theory cannot be distinguished from Bowlby's attachment theory, since both reflect the fundamental nature of the relationship between a mother and her child (Hood, Greenberg, \& Tobach, 1995). In both theories, a strong attachment is presumed to exist between a 
parent and the child from birth, and this relationship becomes stronger as the child demonstrates their complete dependence.

Research has also demonstrated that helping occurs between members of the kinship other than just the mother and child. To test the kin selection theory in an adult population, Burnstein, Crandall, and Kitayama (1994) examined the role of kinship in prosocial behaviors. During their experiments, participants were presented with a scenario such as three people need you to run an errand: your sister, your cousin, and an acquaintance, however you only have time to complete an errand for one person. Participants were instructed to make a choice and results consistently demonstrated a strong association to kin, where the closest individual would be chosen first (e.g., the sister, then the cousin, and the acquaintance last). This trend was consistent across everyday situations, such as running errands, but was even more pronounced in a life or death situation, like choosing one individual to rescue from a burning building. Cunningham, Jegerski, Gruder, and Barbee (1995) verified these results by showing that the percentage of prosocial behavior exhibited is positively correlated with the degree of relatedness. Furthermore, Madsen et al. (2007) have suggested that kinship level is simply a baseline category from which subsequent factors about prosocial behavior are compared (e.g., personal obligation and sense of morals).

Another theory associated with the evolutionary perspective of prosocial behavior is reciprocal altruism. Reciprocal altruism occurs when one engages in a prosocial behavior in order to assist another, however, this is done under the assumption that this help will later be returned. Furthermore, these prosocial actions may decrease the helper's own chances of survival (Trivers, 1971). Trivers explains that one may be more willing to help a non-relative if a better chance of survival is possible. This behavior has been well documented in bats, non-human primates, and humans (Brosnan \& de Waal, 2002; Rapoport \& Chammah, 1965; Wilkinson, 1984). Wilkinson has provided unique evidence and has documented this reciprocal helping behavior in vampire bats. Each evening these bats require a blood meal to keep them satisfied for the night. However, members of this bat species are not always successful at obtaining their nightly meal and death soon becomes a possibility for those with empty stomachs. As a result, this species engages in reciprocal altruism behavior, where one bat will regurgitate their meal in order to feed another starving member. This prosocial behavior ensures the survival of other members, yet is done at the cost of those helping since the helpers will go hungry for the night. From the assumption that these animals do not possess empathy, guilt, or views of morality, one can theorize that these behaviors are biological in origin and can be programmed into ones genetic code.

Reciprocal altruism is also evident in every day human behavior. We all do favors or run errands on the behalf of friends and neighbors, and we do so on the presumption that this favor will one day be returned. In contrast, some may argue that we lend a hand out of genuine kindness and that people do not care if the favor is returned. However, some individuals may not continue to provide favors for an individual that never returns or acknowledges their efforts. Trivers (1983) has identified situations that promote reciprocal altruism. Typically, individuals must live in a society 
where they cannot remain anonymous. Reciprocal altruism is common in communities where "free-loaders" are detected with ease. Furthermore, research has shown that those persons living in rural areas and small towns are more likely to help than individuals who reside in more urban environments (Hedge \& Yousif, 1992).

Additional investigations into the reciprocal altruism hypothesis have been conducted using the prisoners' dilemma task (Axelrod, 1984; Rapoport \& Chammah, 1965). In the classic form of this paradigm, two suspected criminals are placed under arrest and locked in separate holding cells. The police do not have enough evidence to charge them and thus both suspects are offered an identical deal. If one testifies against the other, this prisoner will be released while the other prisoner is given a 10-year jail sentence (called defection). If neither talks, both will receive lighter sentences of 6 months in jail (cooperation). However, if each incriminates the other then both will receive 5 years imprisonment for the crime. Therefore, a strong dilemma is presented: Would you lessen your own punishment at the expense of another? Or do you say nothing in the hopes that your counterpart also remains quiet? Rationally, participants would initially want to defect in order to gain the benefit of release. But most quickly realize that if both prisoners incriminate one another, then the consequences will be severely worse than if they both said nothing. This paradigm is based on the fact that one is unaware of their partner's actions. The prisoners' dilemma game is played over a series of trials and an individual can quickly gauge their partner's tendency to cooperate. This paradigm is highly comparable to the reciprocal altruism theory, which poses a similar question: do you help another in the hopes that he/she will return the favor? The unknown is a hallmark feature within both of these concepts, which subsequently impacts the decision to help. Furthermore, many reciprocal behaviors require a sacrifice on the part of the helper, and thus the rewards are not immediately evident. The prisoners' dilemma is analogous in that participants do not know their partners actions until the games end and therefore are initially unaware if their help (or lack of) was reciprocated.

\section{Empathy-Altruism Hypothesis and Relief of Negative State}

Genetics are only half of the nature-nurture debate, which theorizes that genes may not be the sole contributor to behavior, but that ones' environment and social encounters may possess an equally strong influence (Ridley, 2003). The empathyaltruism hypothesis states that individuals act in a prosocial manner due to internal feelings of empathy toward others (Coke, Batson, \& McDavis, 1978; Batson \& Coke, 1981; Toi \& Batson, 1982). Batson and Coke define empathy as a matching emotional reaction with those persons experiencing the situation; it is also similar to feelings of sympathy, compassion, and tenderness. It is possible that feeling empathy for another is a genetic dispositional trait, although emotional reactions of empathy can instilled in an individual from their environmental encounters. Despite the outcome of this debate, the empathy-altruism hypothesis suggests that an empathetic reaction is primarily responsible for helping behaviors. Coke et al. 
(1978) presented a stage model with two key components to prosocial behavior. First, one must successfully take the perspective of the individual in need. Consequently, taking this perspective will directly increase the emotional response within the observer. Second, an emotional, empathetic response will subsequently lead to prosocial behaviors. Overall, this theory proposes that those who have an authentic concern for the well-being of others are most likely to help. In support of this view, numerous studies have demonstrated that a highly empathetic response is positively associated with helping behaviors (Coke et al., 1978; Toi \& Batson, 1982; Fultz, Bateon, Fortenbach, McCarthy, \& Varoey, 1986; Batson, Duncan, Ackerman, Buckley, \& Birch, 1981). For example, Toi and Batson had participants listen to a radio advertisement of a student who was in an accident, broke both legs, and as a result was now behind in their classes. Participants were then asked how likely they were to help the injured student. Two primary factors were manipulated: the empathy of the radio presentation (high versus low) and the overall cost associated with helping (indexed by the amount of time required to help). Their findings confirmed that empathy was associated with helping. Specifically, those in the high-empathy condition were most likely to help and did so regardless of the cost, while those in the low-empathy condition only helped if the cost was minimal.

Producing an empathetic response is not the only possibility set forth by Batson and colleagues. They also presented the notion that those who help do not do so for self-gratification (Batson, Fultz, \& Schoenrade, 1987). Therefore, bystander actions cannot be interpreted as selfish or egoist in motive. To clarify this hallmark feature, Batson stated that two distinct emotional responses are possible: empathy toward the victim and personal negative distress. As stated previously, by producing an empathetic response one would help in order to alleviate the victim's distress. This is the primary feature of the empathy-altruism hypothesis-that an individual's empathetic concern will lead to altruistic behavior. Conversely, it is also possible that by taking the victim's perspective, one would generate his or her own personal distress (alarm, fear, or anxiety). In this case, the bystander will only help after he/she believes it is the most effective means available to alleviate their own personal suffering. In this situation, help is egoist in nature and is provided purely for self-satisfaction and relief of a personal negative state.

Consequently, the relief of negative state view directly contradicts the assumptions put forth by the empathy-altruism hypothesis (Cialdini, Baumann, \& Kenrick, 1981). Proponents of this theory argue that helping behavior is selfish in nature (Cialdini et al., 1981; Cialdini et al., 1987; Harris, Benson, \& Hall, 1975; Schaller \& Cialdini, 1988; Wallach \& Wallach, 1983). These authors reasoned that prosocial behaviors are expressed mostly due to intrinsic desires to gain self-gratification. For example, as children we are taught to share our toys, play nicely with others in the playground, and to help mom clean up the mess in the living room. When children engage in these helping behaviors without being prompted, they are commonly rewarded and praised by their parents. As children get older, helping behaviors become more complex and parents (and others) still provide rewards. As these prosocial actions are regularly rewarded, they are said to become a conditioned stimulus that increases self-esteem and personal gratification. Thus, when 
bystanders view another person in distress it produces a negative emotional reaction, such as sadness, and most bystanders may help in order to relieve the negative induced state. Cialdini et al. (1987) propose that helping a victim restores the original mood of the bystander, and this happens since most adults have been conditioned to perceive helping as a rewarding stimuli. Thus, these authors conclude that most individuals engage in altruistic behaviors for "an entirely egoistic reason: personal mood management" (p. 750).

Harris et al. (1975) conducted a classic pseudo-investigation into the negative state relief hypothesis of altruistic behavior. These authors requested monetary donations (for a worthy cause) from Roman Catholic parishioners while they were either entering or leaving weekly confession. The donation of money was identified as a measure of altruistic behavior, since the donations were to be sent to those less fortunate. Harris and colleagues discovered that the frequency and the amount of donations were greater from those individuals entering church compared to those persons leaving. Their conclusion pointed to the notion that persons leaving confession were presumed to be absolved on their sins and consequently possessed lesser intrinsic guilt compared to those entering the church. Therefore, the decease in exit donations could primarily be attributed to lessened guilt and relief of a negative internal state. Harris and colleagues conclude that altruistic behaviors could be associated to a current negative self-concept or mood. In summary, a negative mood will most likely lead to helping and altruistic behaviors if the one assumes that this course of action will relieve this distress.

\section{Cost-Reward Model}

While many individuals have a strong empathetic reaction toward those in need of help, there are some who make the decision to not come to the assistance of another. Thus, the empathy-altruism hypothesis may not be fully prepared to explain why this segment of the population fails to provide assistance. Piliavin, Dovidio, Gaertner, and Clark (1981) proposed a simple economic view of prosocial behavior which may account for those individuals who fail to act. These authors posed the assumption that all people have the common goal of maximizing their rewards and minimizing their costs. From this statement, one can presume that individuals undergo an internal cost-reward analysis, where they weigh the costs and benefits associated with helping. There are two broad categories of costs and rewards - those linked with helping and those associated with not helping. Using the cost-reward approach, one can see that most individuals may look at the benefits and penalties of their potential actions. Dovidio et al. (2006) suggest that costs associated with helping may include time, money, danger, embarrassment, and interruption of current activities. In contrast, rewards were identified as money, thankfulness of the victim, praise, fame, and intrinsic pleasure. To summarize, the cost-reward model assumes that as costs increase, helping decreases; and as rewards increase, helping behavior also increases. 
The cost-reward model of altruistic behavior can be linked with Latané and Darley's (1970) stage model of bystander intervention. These researchers hypothesized that there are five fundamental decisions that an individual must make during an emergency. Each of these decisions will eventually lead to one of two opposing outcomes, helping or not. The first of these stages is simple: does an individual notice the event is happening? While it is obvious that emergencies cannot be predicted, a person may not realize that an emergency is occurring. This may be due to proximity and/or the fact that persons are too preoccupied to notice and are therefore not attentive to the situation. On the other hand, others may choose to not pay attention to the event, such as not wanting to get involved in a husband and wife dispute. This first stage assumes that a bystander must recognize an emergency.

Second, an individual must determine if the event is a true emergency. We are not always aware all of the facts surrounding an event. For example, one may see a parked car on the interstate and assume he/she is having car trouble. However, that person may be stopping to take a nap, talk on a cell phone, or be checking a map for directions. It is not always easy to make the determination if there is an emergency. Latané and Darley (1970) hypothesize that if there is an inclination that a situation is a non-emergency, the frequency of helping behavior will drastically be reduced.

The third stage is when a person must assume that it is his/her responsibility to help. Not all individuals feel that it is their responsibility to help out another in need. This personal variable has become a main factor in differentiating those who help and those who remain bystanders to the situation. Latané and Darley (1970) provide additional insight into person's failure to act. They hypothesize two contributors to non-action: diffusion of responsibility and pluralistic ignorance. According to their diffusion of responsibility theory, persons are presumed not to help because they feel like another person has (or will) come to the aid of those in need. Consequently, it is assumed that as the number of bystanders increases, the likelihood that someone will help decreases. Pluralistic ignorance occurs when individuals do not want to make an inappropriate response. For example, one may be reluctant to yell "fire" when they smell smoke in case it may be a false alarm. This stems from the assumption that some individuals would rather not risk embarrassing themselves than initiate help.

The last two factors determine if an individual will engage in helping behavior and may subsequently include the internal cost-reward analysis (Piliavin et al., 1981). The fourth stage is determining if you know what to do and the fifth is making the decision to help. People are less inclined to help if they do not know how to handle the situation. One would most likely not attempt to provide CPR to a choking individual unless they had at least minimal training. Subsequently, he/she must make the final decision: do I help or do I do nothing? This final decision may often times be the most difficult, since there are commonly risks associated with engaging in prosocial behavior. This is where one could engage in a cost-reward analysis as previously described. Dovidio et al. (2006) propose that the degree of help is commonly associated with the outcome of this internal analysis. For example, individuals may realize that sometimes victims may refuse the assistance of others, or bystanders may even be assaulted if they attempt to assist another. These unpleasant 
consequences and concerns may overshadow perceived benefits. These factors may also weigh heavily on a bystander's conscience and he/she may ultimately choose to do nothing.

\section{Belief in a Just World}

The preceding theories of helping behavior relate to the biological and social determinants of helping. However, personal beliefs and assumptions may also play a critical role in one's decision to help following an emergency or natural disaster. In the days following Hurricanes Katrina and Rita, there were many online forums, discussions, television interviews, and web pages that were devoted to how the victims affected by the storms had asked for it. Proponents stated that these victims had chosen to live in neighborhoods that were below sea level, so they were deserving of this destruction in light of their choices. More stated that the government warranted the destruction because they were too incompetent to produce effective levees. Others suggested that New Orleans' nickname The Big Easy implied the residents lived in sin and consequently God wanted the fun-loving, free-spirited, sin-filled city to be destroyed.

These drastic views reflect a belief in a just world, or the conviction that in an orderly and fair world people should get what they rightly deserve (Lerner \& Simmons, 1966; Lerner, 1980). Believers in a just world perceive that good individuals are rewarded and the bad suffer negative consequences. Furthermore, these punishments and rewards are not simply random acts of fate, but are directed towards those who warrant these outcomes. These persons may see victims of emergencies, disasters, and other misfortunes as deserving of their fate. Extreme views suggest that victims may have brought the negative consequences upon themselves.

Justice as a motivator is qualitatively different than other prosocial motivators (Tyler, Boeckmann, Smith, \& Huo, 1997; Blader \& Tyler, 2001). According to Blader and Tyler, the concept of justice prompts an individual to help in order to alleviate injustice, while empathy leads one to help when their emotions and psychological perspective match those of the victim(s). Justice and empathy are usually viewed as a two individual concepts that exert their own unique influence on prosocial behavior (Blader \& Tyler, 2001). Empathetic responses are typically viewed on an individual level, where persons are finding connections and an emotional linkage between themselves and the victim. Justice commonly examines group-fairness and is usually identified as a motivator when the victim is perceived as a collective group of individuals rather than one person.

Consequently, the question exists as to why people are inclined to believe in a just world and use justice as a prosocial motivator? Lerner (1997) has associated belief in a just world to religiosity and views of immortality. The title of his manuscript appropriately addresses the fundamentals of this issue, What does the belief in a just world protect us from: The dread of death or the fear of undeserved suffering? One prominent Christian belief is that a life free of sin will be rewarded with an eternal 
life in heaven after death with God. This can be evidenced with the verse, "For he wages of sin is death; but the gift of God is eternal life through Jesus Christ our Lord"(Romans 6:23, KJV).

Conversely, others who support the view of a just world may simply believe in cause and effect relationships. For example, many persons have a difficult time perceiving their fate as a series of random events (Lerner \& Simmons, 1966; Rubin $\&$ Peplau, 1975). These authors theorize that most find it hard to believe they have no control over the events in their lives; most want to assume that we have some command over our destiny. Therefore, people may presume that if they are good citizens their behavior will be rewarded. Others may trust that those who choose negligence and recklessness will be disciplined and given a punishment. Those who oppose this view may see these negative outcomes as unreasonable and undeserved (Rubin \& Peplau, 1975). These individuals may actually perceive the world as being unjust and as a random series of events; they believe in the possibility that bad things happen to good people.

In sum, these theories just described make an attempt to provide a rational explanation for why people engage in prosocial, altruistic, helping behaviors. The previous section reviewed a variety of questions that all eventually lead to the same fundamental end point of helping. Is there a genetic code programmed into our DNA that elicits prosocial behavior? Is helping the product of an empathetic emotional reaction or is it the result of our own egotistic motives? Do we weigh the pros and cons of helping against one another to determine our actions? Or lastly, do we help because we hold the belief that the world is a fair and just place? All of these questions present probable explanations and but there is one clear fact: people do help. There is a portion of the population that makes the leap from intention to action, and ultimately reaches out to help.

\section{Crossing the Barrier from Intention to Action}

\section{Life Span Development View}

Theories of prosocial behaviors may be useful for understanding helping behaviors generally, but they do not consider an individual's age as a salient characteristic. Perhaps the motivation behind helping varies throughout the life span. Indeed, it seems likely that the motivations of a child may differ compared to those of an adolescent and older adult. This section focuses on age-related changes in helping and prosocial behaviors. Developmental theories associated with helping and other behaviors, such as short-term and long-term volunteering, are also discussed. We address the motivations and patterns of helping prominent in each age cohort. We also outline ways in which volunteer and other humanitarian organizations can increase prosocial activity across each age group.

It has been proposed that there is a cognitive or perceptual switch of helping behaviors from childhood to early adolescence. Cialdini, Kenriek, and Baumann 
(1982) proposed a socialization model that can be applied to the psychology of helping. Cialdini and colleagues suggest that children go through a variety of stages, all of which can influence their motivations and their perceived value of helping. There are three primary stages that children go through, presocialization, awareness, and internalization. Presocialization is when children are simply not aware of the value of helping, nor do they realize that helping is associated with positive reinforcement. Young children may help purely as a way to spend time with their parent or a relative. Children during this period are can be considered passive helpers, meaning that they will act if prompted but helping will most likely not occur spontaneously. As a result, children under age 10 must usually be reminded to pick up their toys, clean their rooms, and help set the table for dinner. Positive associations with these helping behaviors are usually not acknowledged until they transition into the second stage of awareness. Cialdini and colleagues hypothesize that children transition to this stage between the ages of 10 and 12. During this awareness stage, children become increasingly aware that their parents, teachers, friends, and society value helping behavior. These pre-teenagers are more likely to initiate helping their parents, teachers, or friends, but only do so because they are eager to please. Children at this age clean their rooms so their father does not get mad, or may help put the groceries away in order to put a smile on their mother's face. They may also begin to realize that association between helping and reinforcements, such as allowance or various privileges. On the other hand, helping still appears to have no intrinsic reward during this stage; all of the benefits are primarily associated with outside reinforcements. Lastly, children are thought to transition to the internalization stage at around 15 or 16 years old. These adolescents help in order to gain self-satisfaction. Their motivation is internal and they usually help to satisfy a personal need, such as feeling good about themselves or gaining self-confidence.

Development of empathetic responses in second, fourth, and sixth grade children has been examined (Litvack-Miller, McDougall, \& Romney, 1997). During their investigation, the researchers administered altruism questionnaires and a measure to assess each student's level of empathetic concern. The altruism questionnaires provided students with a vignette such as this abbreviated version, One morning Chris was so late getting ready for school that he forgot to eat breakfast... he was really hungry at lunchtime. . . as he unwrapped his sandwich, he noticed a student sitting alone, who looked sad and hungry....he must have forgot his sandwich. Students had to subsequently choose from three potential courses of action. Furthermore, they were provided actual opportunities to make monetary donations or to volunteer for a worthy cause. Results supported the view that those students with a greater empathetic concern were those most likely to help during both the altruism questionnaire and the real life opportunity. Second, this behavior increased with age, where the older students were significantly more likely to help and have empathetic concern than their younger counterparts.

From these views it can be assumed that as children mature there is a gradual change in their motivation for helping. Younger children appear to lack spontaneous motivations to help; they help when ordered and do not recognize external or internal rewards from their actions. Older children progressively realize the external 
associations with helping, such as pleasure and rewards from their parents. Eventually, children not only learn that their helping actions have external rewards but gain an internal benefit as well. These children realize that their actions impact their personal pride, confidence, and pleasure. Consequently, many adolescents engage in long-term helping behaviors, such as volunteering, in order to promote positive growth and reduce juvenile delinquency (Yates \& Youniss, 1996). Previous researchers have further examined the relationship between self-perception and helping, and their results suggest that those adolescents who volunteer on a consistent basis show higher levels on confidence and self-esteem measures (Johnson, Beebe, Mortimer, \& Snyder, 1998; Moore \& Allen, 1996). A similar pattern of results is evident in middle-aged adult populations (Park, 2002). In sum, beginning in early adolescence and continuing on to middle adulthood, the general consensus is that prosocial behaviors are completed because of personal motives, such as self-improvement and self-esteem (Black \& Kovacs, 1999; Omoto, Synder, \& Martino, 2000).

Research into the motivations of volunteerism does not show a strong disparity across age until one reaches older adulthood. For older adults, the motivation behind helping appears to be more about remaining physically active while doing good for society, and less about satisfying their own personal needs (Choi, 2003; Tang, 2006). Twenty-three percent of older adults $(65+)$ contribute to various humanitarian organizations (Bureau of Labor Statistics, 2007). It has been estimated that adults aged 65-74 volunteer approximately 6 hours per week, while those above age 75 average 4.4 hours (Fryock \& Dorton, 1994; Kouri, 1990). Furthermore, when one directly compares the volunteer behavior of both younger and older adults, it is realized that while younger adults (25-36 years) may represent a larger segment of the volunteering population, older adults $(65+$ years $)$ appear to be the more committed segment since they produce the most annual hours (Bureau of Labor Statistics, 2007). This finding may indicate that older adults, while only a small section of the volunteer population, are the most invested, reliable, and stable of all volunteer populations.

Hertzog and Morgan (1993) provide a comprehensive overview of the various predictors significantly associated with volunteerism and prosocial behavior in older adults. These factors include diverse demographic variables and resources such as religion, age, gender, income, educational attainment, marital status, and current level of physical functioning. In recent research paradigms, these factors were analyzed in two distinct populations of 6,465 and 3,617 older adults (Choi, 2003; Tang, 2006). Both of these research paradigms used a predictor model, which wanted to determine those factors most predictive of volunteerism in an older population. Results indicated that importance of religion and church attendance were prominent predictors of volunteerism in older adults. In addition, these results are related to similar research showing that older adults are more likely to act as mentors and counselors in religious organizations compared to younger adults (MorrowHowell \& Tang, 2003). Physical health, such as presence of chronic diseases and self-reported functioning, was also strongly associated with and predictive of 
volunteerism in older adults. This is highly important, since those most likely to volunteer are also probably the healthiest. Education and income served as additional predictors, where an increase in income and education levels was associated with an increase in volunteerism (Choi, 2003; Tang, 2006).

In sum, this literature provides important insight into the factors associated with prosocial behavior in older adults. This segment of the population appears to be a well-equipped and untapped resource for volunteer organizations. Despite the fact that older adults represent a smaller proportion of national volunteers, they appear to be among the most committed to and invested in prosocial efforts. In the future, organizations should make more of an effort to utilize this segment of the population. Tang (2006) presents some considerations and incentives that volunteer communities should offer in order to not only recruit but also ensure the safety of their older adult volunteers. First, it should be recognized that communities will benefit from these older adult volunteers, and thus barriers should be removed or minimized that inhibit this population from engaging in volunteer efforts. Tang further identifies these barriers as such factors like transportation and expenses incurred. Older adults may not be able to drive or lack the necessary funds to pay for the commute. It is also recommended that volunteer organizations should provide transportation vouchers, tax credits, as well as education credits for those older adults who consistently volunteer their time. Offering these rewards and being knowledgeable of age-related concerns may help eliminate factors that may initially prevent one from volunteering.

\section{Disaster Helping Literature}

Disasters bring out demonstrations of humanity in many individuals. Fritz and Williams (1957) state, "During the first few days or weeks following a major community-wide disaster, persons tend to act toward one another spontaneously, sympathetically, and sentimentally, on the basis of common needs rather than in terms of pre-disaster differences in social and economic status" (p. 48). Displays of altruistic behaviors become a prominent response following a disastercommunities come together, neighbors may meet one another for the first time. As Fritz and Williams imply, these humanitarian actions may transcend socioeconomic, age, gender, religious, and racial ties. However, there are several questions that researchers have attempted to answer during the time following a disaster. First, how do individuals personally change in response to a disaster? Second, what factors prompt a sizable portion of the population to help following a community-wide disaster? The answers to these questions provide insight into not only helping behaviors, but the uniqueness associated with a disaster, such as the events of September 11, 2001, the Asian Tsunamis of 2004, and the Gulf Coast storms in 2005.

Peterson and Seligman (2003) investigated personal character changes in individuals following the 9/11 terrorist attacks. Their research addressed the question, of whether there is any change on a personal level in response to a large scale, 
community disasters. While the attacks of 9/11 were associated to distinct communities, its effects were spread across the nation and worldwide. Researchers could not anticipate the onset of this event, and therefore those with pre-disaster data are highly limited. Peterson and Seligman (2003) had previously recruited 4,817 participants from across the United States (87\%) and worldwide (13\%) to complete a character measure, the VIA Inventory of Strengths (VIA-IS). Thus, their research population was not solely limited to participants in directly impacted regions. The VIA-IS is a measurement that assesses personal character strengths, such as hope, kindness, and persistence. The VIA-IS was completed 2 months prior to 9/11. Peterson and Seligman also asked participants to re-complete those measures in the months following the attacks. From the pre- and post-disaster scores, the authors were able to determine any character changes in their population. They found seven primary character strength increases in their population: gratitude, hope, kindness, leadership, love, spirituality, and teamwork. These strengths demonstrated a significant increase across participants in the 2 months following $9 / 11$ and were still elevated (to a lesser extent) during the 10-month follow-up assessment. These results provide insight into the motives behind why people may help in the aftermath of significant disasters. Petersen and Seligman did not assess levels of prosocial behaviors, but one may conclude that an increase in volunteerism could be related to personal character changes.

Further research into the motives behind helping following 9/11 has also been conducted and results have linked altruism with personal identification to the victims (Beyerlein \& Sikkink, 2008). These findings appear to be consistent with the empathy-altruism view of prosocial behavior, where those most likely to help are those who develop an empathetic response toward the victim. Beyerlein and Sikkink demonstrated that their participants formed a personal connection with the victims in drastically different ways. Some individuals felt a strong connection because they actually knew someone who was killed or in danger of being killed during the attacks. Others identified with the victims through media coverage and social events, like candlelight vigils and community prayer sessions. The authors put forth the notion that the emotions expressed following 9/11 prompted individuals to reflect upon their lives and develop a strong connection to the victims, which eventually lead to volunteering for 9/11 relief efforts. In sum, these authors conclude that a strong emotional reaction was likely the key component to altruistic behavior following this specific disaster.

While the circumstances behind 9/11 were fundamentally different than those surrounding Hurricanes Katrina and Rita, there are some underlying similarities between the two events. Both produced extreme levels of devastation and led to an overwhelming emergence of prosocial behavior. In accordance with the majority of disasters, neither of these events was completely anticipated and each received dramatic national coverage. The mass media portrayed both events as utterly devastating and dominated news outlets for significant periods of time. Although the causes of disasters were diverse (man-made versus naturalistic), these disasters produced dramatic destruction and impacted sizeable number of communities. Based 
on these factors, one should presume that investigations into prosocial behavior after disasters follow one comprehensive and unified set of goals.

Research following Hurricane Katrina has identified personal responsibility as a major factor linked with volunteerism (Michel, 2007). This research recruited participants from areas near the capitol of Baton Rouge, which is approximately 80 miles from New Orleans. Baton Rouge was a major triage center following the landfall of Hurricane Katrina (see Cherry, Chapter 9). Approximately 204 participants were asked to complete a personal responsibility assessment by providing a Likert scale answer to the question, "I have a responsibility to use my time to help those affected by Hurricane Katrina." Michel (2007) also assessed the volunteer activity in response to Hurricane Katrina. Using a regression analysis, Michel's study examined the link between personal responsibility and actual volunteer hours. Almost $93 \%$ of persons stated that they felt some level of personal responsibility to use their time to help those affected by the disaster. After controlling for demographic variables such as age, gender, educational attainment, and religion, the results produced a significant link between perceived level of personal responsibility, religious attendance, and volunteer hours in the days following Hurricane Katrina. Therefore, this study provides evidence suggesting that personal attributes, such as feeling personally responsible, can accurately predict altruistic behaviors. These results relate with those provided by Peterson and Seligman (2003) following the attacks of $9 / 11$.

In sum, research following a disaster can be highly difficult to conduct due to the unpredictability of the event and the chaos of the aftermath. Those researchers that have carried out such investigations have consistently found that helping behaviors are apparent in the days and weeks following the event. Even so, there is much we do not about when and why individuals help or do not help following a disaster.

\section{Helping Others in the Aftermath of a Natural Disaster: Findings from the Louisiana Healthy Aging Study}

When Hurricanes Katrina and Rita hit the Gulf Coast region in 2005, the Louisiana Healthy Aging Study (LHAS) had a rare opportunity to assess the influence of the storms on cognitive and physical functioning in adults who ranged in age from their twenties to over ninety years old. The first findings from the LHAS hurricane study are reported elsewhere (see Cherry, Galea, \& Silva, 2008; Cherry, et al., 2009; Cherry et al., Chapter 9). Marks, Cherry, and Silva (Chapter 10) report initial findings from qualitative analyses of responses concerning how participants' religious beliefs and practices helped them cope with Hurricanes Katrina and Rita and their aftermath. We found that "Helping Others" was clearly a dominant theme in this team-based qualitative analysis, which prompted our in-depth focus on the individual level psychology of helping. In the sections that follow, we discuss four data-based themes which relate to the central concern of "helping others." The 
themes are presented in turn, along with primary data excerpts from the participants' interviews for illustration.

\section{Theme 1: Reports of "Being Helped"}

Very few participants discussed help they received, so this first theme has less supporting data than the other themes. Thus, it is listed as a counterpoint, a striking non-finding. Perhaps in a country that values independence above almost all else, it can be highly difficult to discuss receiving assistance. This may be even more so when dealing particularly with life's basic needs, such as food, water, shelter, or clothing. Two of the rare narratives that were shared with us by one woman involved being helped in emotional and spiritual ways versus receiving tangible assistance. She first recalled:

HKR 7, 38 years: I just vividly [remember] in my mind. . . a family from one of the hardest hit areas outside of Grand Isle.... They came. . .about a week or two after the hurricane and sang at our church.... [T] hey lost everything. I mean they lost every picture...everything. I am going to cry just thinking about because it makes me feel [so sad for them]...[but] she was there trying to make us feel better and she had nothing. ... Still to this day, [I remember thinking that day], "You are here and you lost everything and you are singing praises to the Lord."

The same woman also reported an experience during the Katrina aftermath that she interpreted in a way that meant a great deal to her.

HKR 7, 38 years: I just felt like the Lord lead me to this little old lady who was waiting in line [at the store] and she had her grandson [with her]. She had lost her home...she was from New Orleans and lost her home. And in 1994, [she] lost her husband....[but] she said, with joy in her heart, "God closes one door and opens another." [S]he said, "Now I am blessed everyday day to be with my [two-year old] grandson...I am home with him everyday..." [I]t was just a real testament to her strength. [Also, when he was still a little boy] her [now grown] son... was in coma and. . .there was nothing [they could] do, [but] her son ended up living and now is. . the head of [a department] at [a large hospital]. [The lady said], "God saved him so that he can save all these others." ... It was just a real dramatic thing just in the grocery store... God led me to her.

In both of the above narratives, this woman describes being lifted and helped by the example and attitude of persons who had lost far more than she did in Katrina. However, similar stories of being "helped" were exceptionally rare among our participants.

\section{Theme 2: Pride Through Association with a Faith Community}

One recurring theme in our data was the tendency of participants to express pride in their specific church's involvement in helping those affected by Hurricane Katrina. Of these participants, many offered the specific names of their faith communities. 
Interestingly, most of those who explicitly drew attention to their faith communities also admitted that they were not involved in assisting in a hands-on manner.

(Related statements are italicized for emphasis.)

HKR 111, 53 years: My church played a very active role [helping Katrina victims]. It's [church name and denomination] downtown.... My church played a very active role in feeding, clothing and housing and they were a distribution point for a lot of FEMA supplies coming in. They were kind of the central point for trucks coming and other trucks coming out. I did not participate in that. . .but I was very proud to know that was happening. Then they also used a lot of the Sunday school classrooms for schooling for the evacuees so I just thought [that] was just fabulous. So I was very proud of my church. Even though I had nothing to do with it.

HKR 2, 32 years: I was very...happy with my church's response to the situation. My husband and I were both just (so involved) with our jobs...that we weren't really able to volunteer but it helped to know that the church that we belong to, that we give money to, [was] helping.... They housed different people at the church, so it helped to know that we were a part of that...

HKR 9, 42 years: I just don't know how people could get through that without his help. That's all I can say. ... I know that the church that we are members of, they were very helpful with people who needed help and that sort of thing.

HKR 11, 27 years: [My] church was very supportive, collecting clothes, and food, and giving shelter and offering prayer services... and they had a blood drive.

HKR 13, 46 years: [T] he young men [from my church] would go out there [to the hard hit areas], and they would...pick a neighborhood, go down the street, cut trees down off people's houses. And [people would] say, "Let us pay you." "No," the young men said, "We're doing God's work." And they would just go through [and help] and people were just amazed. [S]o our church really did [a lot]...

One person who referred to her specific church, also readily acknowledged the efforts of other churches as well. She reported:

HKR 118, 49 years: Well, I am [denomination] and the church we belong to helped out. [But]. . .it [was] all the churches; it wasn't just ours. All the churches opened the churches and their families and their houses if they could. Everything was opened up to everybody. Almost all the churches around here [helped out].

Individuals are often deemed "guilty by association" due to questionable company they keep. It seems that we are seeing a converse principle in action, a kind of "exoneration by association." Exonerated from what?: the charge of doing nothing to help those who desperately needed it. From a psychological vantage, the pattern in the above statements is an interesting one. Although no questions explicitly addressed the question, participants repeatedly reported the involvement and efforts of "their" churches and the pride and happiness they took in this involvement, in spite of a lack of personal, firsthand contribution. This pattern leads us to a closely related theme, that of ethics and intentions. 


\section{Theme 3: The Road Paved with Good Intentions, Noble Phrases, and Ethics}

Some of our participants referred specifically to their desire to help. Likewise, many of our participants pontificated on what we "should" and "ought" to do in situations like Hurricanes Katrina and Rita. Here are several examples:

HKR 203, 82 years: ... [We need] to be caring individuals, to love one another, and to also try to help take care of one another. And I think when. . you have people who care, then that helps you through these trying times. Now we have brought that [kind of spirit] together into organizations - our institutions of churches. And [because of] them, we have better unified, organized [ways] to help people out....

HKR 303, 92 years: [You should] be willing and able to help your neighbor if he's in trouble or needs help. Share what you have.... It's the old saying, "You are your brother's keeper."

HKR 109, 59 years: My personal philosophy is that each of us is suppose to live with virtue for virtue's sake, and try to do the best you can and help your fellow man when you can and do what is right.

HKR 118, 49 years: [M]y beliefs were always...help when you can help. Always help others and we have always done that. I guess you do it more when there is a disaster.

HKR 212, 65 years: My religion has taught me to help people [and that] you are supposed to help people no matter what or what circumstances.

HKR 213, 78 years: I think that as humans on this earth, we are to help our fellow men...when and where we can.

With these things noted, we move to the final theme-one that focuses on those who did cross the canyon, so to speak, to offer their tangible assistance.

\section{Theme 4: Bridging the Belief-to-Behavior Gap}

We now turn our attention to some individuals who did bridge the "belief-tobehavior gap" by converting positive ethics and intentions into action.

HKR 2, 32 years: I had always wondered what difference one person could make and in this situation it showed me that I do have some impact on other people. And it was very strange because I would get up in the mornings and I thought, "Oh gosh. I have got to find housing for this person and this person and this person. I can't do this by myself! No one else has a clue. Nobody has a clue. The State doesn't have a clue. What am I supposed to do?" [But things seemed to work out]. . .So it strengthened me.

HKR 5, 31 years: In situations like Hurricane Katrina, [that's] where the rubber meets the road. You either say what you believe and then do something to show [it and] your actions meet up with that - or you just say a bunch of stuff and do the opposite. And I think that knowing what I believe and the hope that I have, it kind of just makes you only want to share that and give that hope to someone else. I feel like we didn't have a whole lot of damage to our house so we were able to not have to spend any time fixing up our stuff and taking care of our needs. We were able to just go right out and help others and minister to them.

HKR 15, 39 years: [A]fter the storms. . the main thing that I can see that actually has come out of it for me is... it has been a humbling experience and it has changed my life in a way that I really can't even explain. [H]elping [other] people, that [is what] helped me to cope.... I took on so much other stuff helping other people [that] it kind of drowned out what I was going through and God fixed it. So while I was trying to fix somebody else['s 
situation], God was fixing mine. I. . .just continued to stay in prayer and helped those that needed help [and in the process, God helped me].

HKR 116, 52 years: [After Katrina] I realized that there would be people that would never find their family members, you know. When you go to those [emergency] sites and see how many people were looking for [family and loved ones]... and the more that you talk to people at the shelters and see their eyes and [and their faces] and [see] what they are going through, [the less you think about your own worries].

HKR 213, 78 years: I tried to help people, those people who were hurting. The most. . the thing that I felt that I could do at my stage in life was to help them through feeding them and helping to clothe them. I sorted clothes by sizes, and then I served them.... I felt that I. . .I felt that I was contributing.

HKR 312, 91 years: I [gave] them the last dollar I had to buy food. It was even more than what I got in the house. I don't want to see them hungry. That's the only thing I know to do. That's the only [help I could give]. ...People can help you, but they can't do for you what God can do.

We suspect that some of the more dramatic stories of human kindness were not told. Perhaps, such stories are veiled by simple, laconic phrases like these two:

HKR 101, 62 years: [We] do the best we can to help...each other.

HKR 110, 49 years: We have done what we can to try to help people....and that's pretty much it.

In summary, we learned a handful of lessons from our participants. First, these people were not anxious to discuss ways in which they had received assistance. Second, many participants were anxious to express pride through association with their churches - even when they had little or no firsthand role personally. Third, many participants spontaneously discussed the abstract importance of helping "brothers and sisters." Fourth, most struggled to convert their personal ethics and intentions into deliberate action. Those of us on-site in Louisiana who lived through that time will not judge them too harshly, as we recollect our own pain, grief, and disbelief in the aftermath of Hurricanes Katrina and Rita. Finally, while we must acknowledge that while most of our participants were not heroic in the face of these challenges, a select few were remarkable helpers. As a group of participants from across the adult life span, there is much we can learn, both in terms of human tendency and in terms of human potential in the face of a natural disaster.

\section{Conclusion}

We opened this chapter with a selective literature review of the psychology of helping with coverage of topics and theories of the origins of prosocial behaviors. This chapter also documented the gradual, developmental progression of age-related, altruistic motivations. We addressed issues specific to a disaster by discussing prospective studies from 9/11 and Hurricanes Katrina and Rita. Qualitative data from LHAS participants who experienced the aftermath of Hurricanes Katrina and Rita yielded four central lessons, as follows. From Theme 1, we learned that the participants in our study were reluctant to mention, much less discuss, receiving assistance in the aftermath of the hurricanes. In Theme 2, we were reminded 
that faith communities and organizations were active players in post-hurricane help efforts. Most of the LHAS participants reported a religious affiliation and many of those were quick to draw attention to help that their church had provided, while confessing that they had done little or nothing themselves-a pattern we called "exoneration by association." In Theme 3, we illustrated that many of the participants spontaneously addressed the ethic of helping others, as well as their intentions to put those ethics into action-indicating that the psychological dilemmas regarding who, how, and when to help (as discussed in our review of literature) were very real to them. Theme 4 illustrated two realities. First, that most of the ethics and intentions aimed at helping others were not converted into action. Second, however, a few persons did bridge the belief-to-behavior gap by helping in significant wayseven to the point of a woman giving her last dollar. In closing, we learn from our participants that people often fail to meet their own standards in helping after a crisis. Yet, if some are not as noble as we might hope...some exceed our expectations and present new possibilities.

Acknowledgment We thank Tracey Frias, Miranda Melancon, and Zia McWilliams for their assistance with data summary and qualitative analyses. We also thank Erin C. Goforth for her helpful comments on an earlier version of this manuscript.

This research was supported by grants from the Louisiana Board of Regents through the Millennium Trust Health Excellence Fund (HEF[2001-06]-02) and the National Institute on Aging P01 AG022064. This support is gratefully acknowledged.

\section{References}

Axelrod, R. (1984). The evolution of cooperation. New York: Basic Books.

Batson, C. D., \& Coke, J. S. (1981). Empathy: A source of altruistic motivation for helping? In P. Rushton \& R. M. Sorrentino (Eds.), Altruism and helping behavior: Social, personality, and developmental perspectives (pp. 167-187). Hillsdale, NJ: Erlbaum.

Batson, C. D., Duncan, B. D., Ackerman, P., Buckley, T., \& Birch, K. (1981). Is empathic emotion a source of altruistic motivation? Journal of Personality and Social Psychology, 40, 290-302.

Batson, C. D., Fultz, J., \& Schoenrade, P. (1987). Distress and empathy: Two qualitatively distinct vicarious emotions with different motivational consequences. Journal of Personality, 55, 19-39.

Beyerlein, K., \& Sikkink, D. (2008). Sorrow and solidarity: Why Americans volunteered for 9/11 relief efforts. Social Problems, 55, 190-215.

Black, B., \& Kovacs, P. J. (1999). Age-related variation in roles performed by hospice volunteers. Journal of Applied Gerontology, 18, 479-497.

Blader, S. L., \& Tyler, T. R. (2001). Justice and empathy: What motivates people to help others? In M. Ross \& D. T. Miller (Eds.), The justice motive in everyday life (pp. 226-250). New York: Cambridge University Press.

Bowlby, J. (1969). Attachment and loss (Vol. I). London: Hogarth.

Bowlby, J. (1988). A secure base: Clinical applications of attachment theory. London: Routledge Press.

Brosnan, S. F., \& de Waal, F. B. M. (2002). Approximate perspective on reciprocal altruism. Human Nature, 13, 129-152.

Bureau of Labor Statistics. (2007). Volunteering in the United States, 2007. Retrieved September 30, 2008, from, http://www.bls.gov/news.release/volun.nr0.htm

Burnstein, E., Crandall, C., \& Kitayama, S. (1994). Some neo-Darwinian decision rules for altruism: Weighing cues for inclusive fitness as a function of the biological importance of the decision. Journal of Personality and Social Psychology, 67, 773-789. 
Cherry, K. E., Galea, S., \& Silva, J. L. (2008). Successful aging and natural disasters: Role of adaptation and resiliency in late life. In M. Hersen \& A. M. Gross (Eds.), Handbook of clinical psychology (Vol. 1, pp 810-833). New Jersey: John Wiley \& Sons, Inc.

Cherry, K. E., Galea, S., Su, L. J., Welsh, D. A., Jazwinski, S. M., Silva, J. L., et al. (2009). Cognitive and psychosocial consequences of Hurricanes Katrina and Rita on middle aged, older, and oldest-old adults in the Louisiana Healthy Aging Study (LHAS). Journal of Applied Social Psychology (in press).

Choi, L. H. (2003). Factors affecting volunteerism among older adults. The Journal of Applied Gerontology, 22, 179-196.

Cialdini, R. B., Baumann, D. J., \& Kenrick, D. T. (1981). Insights from sadness: A three-step model of the development of altruism as hedonism. Developmental Review, 1, 207-223.

Cialdini, R. B., Kenriek, D. X., \& Baumann, D. J. (1982). Effects of mood on prosocial behavior in children and adults. In N. Eisenberg (Ed.), The development of prosocial behavior (pp.339359). New York: Academic Press.

Cialdini, R. B., Schaller, M., Houlihan, D., Arps, K., Fultz, J., \& Beaman, A. (1987). Empathybased helping: Is it selflessly or selfishly motivated? Journal of Personality and Social Psychology, 52, 749-758.

Coke, J. S., Batson, C. D., \& McDavis, K. (1978). Empathic mediation of helping: A two-stage model. Journal of Personality and Social Psychology, 36, 752-766.

Cunningham, M. R., Jegerski, J., Gruder, C. L., \& Barbee, A. P. (1995). Helping in different social relationships: Charity begins at home. Unpublished manuscript, University of Louisville.

Dovidio, J. F., Piliavin, J. A., Schroeder, D. A., \& Penner, L. A. (2006). The social psychology of prosocial behavior. New Jersey: Lawrence Erlbaum.

Eisenberg, N., \& Fabes, R. A. (1998). Prosocial development. Handbook of child psychology (5th ed., Vol. 3, pp. 701-778). New York: Wiley and Sons.

Fryock, C. D., \& Dorton, A. M. (1994). Unretirement: A career guide for the retired. . .the soon-to be retired. . the never-want-to-be retired. New York: American Management Assoc.

Fultz, J., Bateon, C. D., Fortenbach, V. A., McCarthy, P. M., \& Varoey, L. L. (1986). Social evaluation and the empathy-altruism hypothesis. Journal of Personality and Social Psychology, 50, 761-769.

Fritz, C., \& Williams, H. 1957. The human being in disasters: A research perspective. Annals of the American Academy of Political and Social Science, 309, 42-51.

Hamilton, W. D. (1963). The evolution of altruistic behavior. American Naturalist, 97, 354-356.

Hamilton, W. D. (1964). The genetical evolution of social behaviour: I and II. Journal of Theoretical Biology, 7, 1-16 and 17-52.

Harris, M. B., Benson, S. B., \& Hall, C. L. (1975). The effects of confession on altruism. Journal of Social Psychology, 96, 187-192.

Hedge, A., \& Yousif, Y. H. (1992). Effects of urban size, urgency, and cost on helpfulness: A crosscultural comparison between the United Kingdom and the Sudan. Journal of Cross-Cultural Psychology, 23, 107-115.

Hertzog, A. R., \& Morgan, J. S. (1993). Formal volunteer work among older Americans. In S. A. Bass, F. G. Caro, \& Y. P. Chen (Eds.), Achieving a productive aging society (pp. 119-12). Westport, CT: Auburn House Press.

Hood, K. E., Greenberg, G., \& Tobach, E. (1995). Behavioral development: Concepts of approachwithdrawal and integrative levels. The T. C. Schneirla Conference Series, Vol. 5. New York: Garland.

Indiana University Center on Philanthropy. (2007). Giving in the aftermath of the gulf coast hurricanes. Retrieved on September 29, 2008, from, http://foundationcenter.org/gainknowledge/ research/pdf/katrina_report_2007.pdf

Johnson, K., Beebe, M. T., Mortimer, J. T., \& Snyder, M. (1998). Volunteerism in adolescence: A process perspective. Journal of Research on Adolescence, 8, 309-332.

Kouri, M. K. (1990). Volunteerism and older adults. Santa Barbara, CA: ABC-CLIO Press.

Latané, B., \& Darley, J. (1970). The unresponsive bystander: Why doesn't he help? New York: Appleton-Century-Crofts Press. 
Lerner, M. J. (1980). The belief in a just world: A fundamental delusion. New York: Plenum.

Lerner, M. J. (1997). What does the belief in a just world protect us from: The dread of death or the fear of understanding suffering? Psychological Inquiry, 8, 29.

Lerner, M. J., \& Simmons, C. H. (1966). The observer's reaction to the 'innocent victim': Compassion or rejection? Journal of Personality and Social Psychology, 4, 203-210.

Litvack-Miller, W., McDougall, D., \& Romney, D. M. (1997). The structure of empathy during middle childhood and its relationship to prosocial behaviour. Genetic, Social and General Psychology Monographs, 123, 303-325.

Madsen, E. A., Richard, J., Fieldman, G., Plotkin, H. C., Dunbar, R. I. M., Richardson, J., et al. (2007). Kinship and altruism: A cross-cultural study. British Journal of Psychology, 98, 339-359.

Michel, L. (2007). Personal responsibility and volunteering after a natural disaster: The case of hurricane Katrina. Sociological Spectrum, 27, 633-652.

Moore, C. W., \& Allen, J. P. (1996). The effects of volunteering on the young volunteer. The Journal of Primary Prevention, 17, 231-258.

Morrow-Howell, N., \& Tang, F. (2003). Elder service and youth service in comparative perspective: Nature, activities, and impacts. St. Louis, MO: Washington University, Center for Social Development [Working paper].

Omoto, A. M., Synder, M., \& Martino, S. C. (2000). Volunteerism and the life course: Investing age-related agendas for action. Basic and Applied Social Psychology, 22, 181-197.

Park, G. J. (2002). Factors influencing the meaning of life for middle-aged women. Korean Journal of Women's Health Nursing, 2, 232-243.

Peterson, C., \& Seligman, M. E. P. (2003). Character strengths before and after September 11. Psychological Science, 14, 381-384.

Piliavin, J., Dovidio, J. F., Gaertner, S. L., \& Clark, R. (1981). Emergency intervention. New York: Academic Press.

Pyszczynski, T., Solomon, S., \& Greenburg, J. (2003). In the wake of 9/11: The psychology of terror. Washington, DC: American Psychological Association.

Rapoport, A., \& Chammah, A. M. (1965). Prisoner's dilemma. Ann Arbor: University of Michigan Press.

Ridley, M. (2003). Nature via nurture: Genes, experience, and what makes us human. New York: Harper Collins Press.

Rubin, Z., \& Peplau, L. A. (1975). Who believes in a just world? Journal of Social Issues, 31, $65-89$.

Schaller, M., \& Cialdini, R. B. (1988). The economics of empathic helping: Support for a mood management motive. Journal of Experimental Social Psychology, 24, 163-181.

Tang, F. (2006). What resources are needed for volunteerism? A life course perspective. The Journal of Applied Gerontology, 25, 375-390.

Toi, M., \& Batson, C. D. (1982). More evidence that empathy is a source of altruistic motivation. Journal of Personality and Social Psychology, 43, 281-292.

Trivers, R. L. (1971). The evolution of reciprocal altruism. Quarterly Review of Biology, 46, 35-57.

Trivers, R. L. (1983). The evolution of cooperation. In D. L. Bridgeman (Ed.), The nature of prosocial development. New York: Academic Press.

Tyler, T. R., Boeckmann, R. J., Smith, H. J., \& Huo, Y. J. (1997). Social justice in a diverse society. Boulder: Westview.

Wallach, M. A., \& Wallach, L. (1983). Psychology is sanction for selfishness: The error of egoism in theory and therapy. New York: W.H. Freeman and Company.

Wilkinson, G. S. (1984). Reciprocal food sharing in the vampire bat. Nature, 308, 181-184.

Yates, M., \& Youniss, J. (1996). A developmental perspective on community service in adolescence. Social Development, 5, 85-115. 